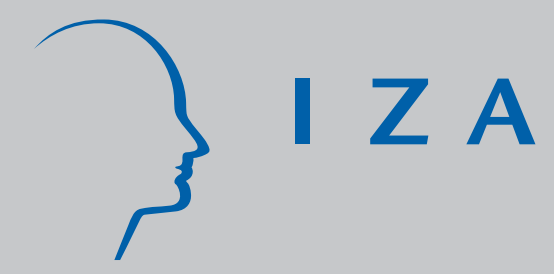

IZA DP No. 1426

Initial Luck, Status-Seeking and Snowballs Lead to Corporate Success and Failure

Amihai Glazer

Vesa Kanniainen

Panu Poutvaara

December 2004 


\title{
Initial Luck, Status-Seeking and Snowballs Lead to Corporate Success and Failure
}

\author{
Amihai Glazer \\ University of California, Irvine \\ Vesa Kanniainen \\ University of Helsinki, \\ CESifo and HECER

\section{Panu Poutvaara} \\ CEBR, CESifo \\ and IZA Bonn
}

\section{Discussion Paper No. 1426 \\ December 2004}

\author{
IZA \\ P.O. Box 7240 \\ 53072 Bonn \\ Germany \\ Phone: +49-228-3894-0 \\ Fax: +49-228-3894-180 \\ Email: iza@iza.org
}

\begin{abstract}
Any opinions expressed here are those of the author(s) and not those of the institute. Research disseminated by IZA may include views on policy, but the institute itself takes no institutional policy positions.

The Institute for the Study of Labor (IZA) in Bonn is a local and virtual international research center and a place of communication between science, politics and business. IZA is an independent nonprofit company supported by Deutsche Post World Net. The center is associated with the University of Bonn and offers a stimulating research environment through its research networks, research support, and visitors and doctoral programs. IZA engages in (i) original and internationally competitive research in all fields of labor economics, (ii) development of policy concepts, and (iii) dissemination of research results and concepts to the interested public.
\end{abstract}

IZA Discussion Papers often represent preliminary work and are circulated to encourage discussion. Citation of such a paper should account for its provisional character. A revised version may be available directly from the author. 
IZA Discussion Paper No. 1426

December 2004

\section{ABSTRACT}

\section{Initial Luck, Status-Seeking and Snowballs Lead to Corporate Success and Failure*}

Corporate success often resembles a snowball. We show how initial luck in hiring talented people, the resulting technological advantage, superior corporate culture, and status-seeking by workers can make small initial differences generate large differences over time.

JEL Classification: LO0, L13

Keywords: industry equilibrium, initial luck, status effects, snowball

Corresponding author:

Panu Poutvaara

CEBR

Copenhagen Business School

Porcelaenshaven, Bldg 65

2000 Frederiksberg

Denmark

Email: panu.poutvaara@cebr.dk

\footnotetext{
* An earlier draft of this paper was presented at the CESifo Area Conference on Industrial Organization, Munich, March 12-13, 2004. The authors are indebted to Kai Konrad, Vivek Ghosal and other participants for helpful comments. We are also grateful to Thomas Rønde for his suggestions.
} 


\section{Introduction}

The late 1990s were revolutionary in many markets for high-technology products. Companies were created from scratch, with some dramatic successes and failures. In the market for mobile phones, several producers invested heavily in $R \& D$ programs to capture the network effects among consumers. But by 2001 only one firm, Nokia, was profitable, with $50 \%$ annual growth in some years; its market share reached $39 \%$ by 2003 . All its competitors, including the well-established Ericsson and Motorola suffered large losses. As this example suggests, corporate success stories often resemble a snowball. Small initial differences may lead firms producing similar products to end in far different situations.

Among the other examples of a snowball phenomenon is the contest between VHS and Betamax standards for video tapes, with only VHS surviving. The idea that small initial differences can result in vastly differing equilibria is prominent in chaos theory and in macroeconomic models with unstable paths. We explain how similar outcomes can occur in an industry.

A firm may have gained a competitive advantage through luck. For example, it may have been luckier than its competitors in hiring more talented workers or workers who can better work with each other. This could lead to lower costs, or to products which better satisfy consumer desires. This can generate dynamic repercussions, with the success of a firm in one period increasing its chances of success in later periods.

Several mechanisms can generate such a snowball effect and our specific results relate to how they arise. For concreteness and for analytical convenience we shall concentrate on two mechanisms. First, we suppose workers gain status from working at a successful firm, allowing the firm to attract better workers at lower pay. People who care what others think of them may view working for a firm with a good reputation as increasing their esteem. The phenomenon is well known at universities - faculty are attracted to Harvard for its prestige, not only for the salaries or environment it offers. Law school graduates evaluate each other by the reputation of the law firms which offered them jobs, or the prestige of the judge who offered them clerkships. In contrast, working in a prison or in garbage collection offers little prestige, even if the wage is higher than alternatives the workers might find.

Second, we suppose that good workers generate a good corporate culture, which contributes to future performance. The corporate culture at a firm may reflect the identity 
of its workers in the past: the higher the quality of workers in the past, the better its procedures and traditions, and so the more successful it will be in the future. ${ }^{1}$ We may also think of current workers hiring new workers, with high-quality workers better at identifying the quality of job applicants. Here again, the past quality of workers at a firm will affect profits in later periods. Moreover, if capital markets are imperfect, a firm that was successful in the past may have sufficient assets to survive periods of low profits, and may therefore be less likely to fire its workers. The increased job security can allow the firm to pay lower wages in the future. At a more psychological level, success can increase the morale and enthusiasm of workers, making them more productive the greater their success has been in the past.

Such path dependence may explain the evolution of firms within some industries. Thus, the different fortunes of Nokia and Ericsson may have arisen from small initial differences in the quality of their workers, reflected in small differences in the products. (Casual observation suggests that Nokia's phones were more elegant than Ericsson's, and had longer-lasting batteries). The puzzle is that Nokia increased its dominance under several major technological changes, where its previous technological lead appeared to have little relevance to the new technologies. And we nevertheless wish to allow the dominant firm to falter, as Nokia did in 2003-2004 when it saw its market share decline.

\section{Literature}

Important theoretical articles on industry dynamics include Jovanovic (1982), Hopenhayn (1992), and Ericson and Pakes (1995). Jovanovic (1982) has heterogeneous firms learn over time about their productivity and either expand or exit. Hopenhayn (1992) considers firms which experience persistent shocks to technology, studying changes in size distribution and in turnover rates. Ericson and Pakes (1995) study investments in new processes,

\footnotetext{
${ }^{1}$ If corporate culture is embodied in the firm's workers (as in Jovanovic (1979), Prescott and Visscher (1980), and Becker (1993) suppose), then as Arrow (1974) shows, a firm's culture can be path dependent, and culture can vary across firms. The path dependence can be stronger if management selects workers whose preferences it prefers (Lazear (1995)), or if a worker prefers to work at a firm with a culture fitting his background. This preference resembles the peer-group effect in schooling, which has been much studied by Epple and Romano (1998). Becker examines discrimination when workers care who their co-workers are. Ma (2001) models the peer-group effect at the workplace.
} 
with uncertainty about the outcomes. Klepper (1996) explains shakeout as resulting from dominance by large firms which enjoy a scale advantage in refining production processes. Jovanovic and MacDonald (1994) see firm exit as occurring among firms which fail to innovate.

We look behind the technological changes, explaining how firms may come to differ in their ability to innovate, and explaining why a firm which innovated in previous periods has an advantage in innovating in future periods. The topic of increasing dominance, whereby a successful firm becomes yet more successful in future periods, has been the subject of several insightful papers. A unifying treatment is found in Athey and Schmutzler (2001). They show that a firm with low costs or high quality will extend its initial lead through investments if (1) investment by a firm reduces the profits of other firms; (2) product market payoffs are convex in the state variable; (3) adjustment costs do not rise too quickly with the level of the state variable. These conditions will be met for example in a duopoly, where a firm which has more demand has greater incentive to invest than does a firm with lower demand, or in an industry with learning by doing effects. A different explanation for increasing dominance is given by Cabral (2002), who shows that when a firm's profits increase with the difference between what it does and its competitor does, a lagging firm may prefer to follow in an investment path that is less promising than the investment path chosen by the leading firm.

In our model we need not assume that the profit function is convex, that is, we need not assume that the leader has more to gain from extending his lead than the laggard has to lose from falling farther behind. Rather, our consideration of status effects and of differences in corporate culture can make an initially lucky firm enjoy lower costs in the future; this generates results related to, but differing from, those that arise from learning by doing.

Our assumption that people care about status, rather than exclusively about absolute income, is common in the literature. Rae (1834) and Mill (1847) consider such a motive. The behavior of consumers who signal income is studied by many economists since then, most elegantly in the work of Frank (1984a, 1984b, 1985a, 1985b). Frank also considers workers who care about their prestige within a firm, so that a person at the bottom of the wage scale demands a premium to work with richer people, and a person at the top of the scale is willing to trade off income for status. Our analysis complements Frank's 
by considering status of a worker as viewed by persons outside the firm, rather than by co-workers. In small cities, or in cities with a dominant employer, relative status within a firm may be most important. In large cities with many employers, status as observed by people outside the firm may be more important. The status effect we model differs from the analysis in Fershtman, Weiss, and Hvide (2001), who consider self-esteem which rises with a worker's wage. We see a successful firm as preferring to hire workers with low self-esteem, but who seek the social approval obtained from working at a successful firm.

Studies of discrimination in the labor market use related ideas. In his classic book, Becker (1957) explores a model where some individuals in a group prefer to work with persons of the same group. Under factor price equalization this leads to segregation in different sectors. Borjas (1982) assumes that white constituents prefer to be served by white clerks in a government agency, and that blacks prefer to be served by blacks. Arrow (1972) supposes that some whites do not like to work with blacks.

The idea that a person's utility varies with the types of persons belonging to the same organization is found in some analyses of clubs. Scotchmer (1992) proves the existence of a unique competitive equilibrium, which is also Pareto optimal. Berglas (1976), Brueckner (1991), and McGuire (1991) study the characteristics of a competitive equilibrium when firms hire workers with different skills. Attention has also been given to schooling, where the presence of able students improves the performance of less able students (see Arnott and Rowse (1987) and De Bartolome (1990)).

\section{Assumptions}

There are two firms. ${ }^{2}$ Each hires workers to develop new technologies and produce goods with new features. We start with investment in a single period, each firm working on a new technology. We then consider firms which compete in producing additional features within the available technology. Lastly, we consider the fully dynamic problem where firms compete in developing new technologies over an infinite horizon.

Initial luck in R\&D. At the beginning of the period, the two firms $(A$ and $B)$ are identical. Each is uncertain about what product features consumers will value. Workers

\footnotetext{
${ }^{2}$ The number of firms is fixed because ability to innovate is a scarce resource.
} 
develop a product, with features consumers value at $f_{i}$ for firm $i$ 's product. The features may include ease of operating the product, weight, color, shape, and so on. The outcome of a firm's investment, which we do not model, is random. After the investments are made, nature determines the relative merits of the outcomes, say $f_{A}-f_{B}=\delta$. One firm, say $A$, has a better product than the other; $\delta$ is then positive. A natural interpretation for the difference in the outcomes is that some firm is lucky in hiring workers who better know consumer preferences than do workers in the other firm.

Consumers: product features and fads. Consumers are willing to pay more for the better product, with the premium $\delta=f_{A}-f_{B} \geq 0$. For most of our purposes, it does not matter whether the firm with the better product does or does not gain all the market: increased market share in one period does not give a firm any advantage in following periods. But to show that our results can also appear when both firms sell goods in any period, we shall suppose that consumers differ in their willingness to pay for the good produced by one firm over another. To avoid excessive notation, it is convenient to identify the firms solely by which has the better product in any period. We therefore make the following assumption: consumers are willing to pay a premium for the better product, but consumers differ in the amount of the premium they are willing to pay. ${ }^{3}$ Note, incidentally, that this assumption can capture in a rudimentary way a network effect, with consumers willing to pay more for the more popular product. We shall call this the fad effect. As with many fads, they can be passing, with the firm benefitting from a faddish demand in one period losing that demand if it does not have the faddish product next period.

In particular, a consumer is willing to pay more for the better (more faddish) product, regardless of its absolute quality. We index consumers according to the value they place on consuming the more faddish product, with consumer $i$ valuing the fad at $s_{i} \cdot{ }^{4}$ If the two products are of the same quality, faddish considerations are irrelevant. The mass of consumers is 1 , and $s_{i}$ is uniformly distributed between zero and one.

The price of good $i$ is $p_{i}$. For any given values of $p_{A}, p_{B}\left(\right.$ with $\left.p_{A}>p_{B}\right), f_{A}$, and $f_{B}$,

\footnotetext{
${ }^{3}$ Other factors could also lead both firms to produce: increasing marginal cost of production could limit the amount the producer of the better goods wants to produce; the firms may be located at different locations, with consumers preferring the closer firm; the products may differ in some attributes which some consumers value and others do not.

${ }^{4}$ As an example, grandmothers seldom regard a portable phone as faddish. Teenagers do.
} 
there exists a critical value of willingness to pay for faddishness, $\widehat{s}$, such that consumers with a higher value buy good $A$, and others buy good $B$. If $\widehat{s} \in(0,1)$ sales at both firms are positive, and the following indifference condition for the marginal consumer is satisfied:

$$
f_{A}+\widehat{s}-p_{A}=f_{B}-p_{B}
$$

Consumers with $s<\widehat{s}$ buy product $B$; the others buy product $A$. The share of consumers buying product $B$ is

$$
\widehat{s}=f_{B}-f_{A}+p_{A}-p_{B}
$$

\section{Market equilibrium}

To emphasize the importance of fixed costs in R\&D, we assume that the marginal cost of production is zero. The two firms engage in Bertrand competition. Firm A's objective is to

$$
\max _{p_{A}}\left(1-f_{B}+f_{A}-p_{A}+p_{B}\right) p_{A}
$$

resulting in

$$
p_{A}=\frac{1+p_{B}-f_{B}+f_{A}}{2} .
$$

Firm $B$ 's objective is to

$$
\max _{p_{B}}\left(f_{B}-f_{A}+p_{A}-p_{B}\right) p_{B}
$$

resulting in

$$
p_{B}=\frac{p_{A}+f_{B}-f_{A}}{2} .
$$

Equations (4) and (6) imply that the prices are

$$
p_{A}=\frac{2-f_{B}+f_{A}}{3}
$$

and

$$
p_{B}=\frac{1+f_{B}-f_{A}}{3} .
$$

For firm $B$ to charge a non-negative price, $f_{A}-f_{B}$ must be less than 1 . The market share of firm $B$ is

$$
\widehat{s}=\frac{1+f_{B}-f_{A}}{3} .
$$


We see that the market share of firm $B$ cannot exceed 1/3. Faddish considerations make the upper limit bind. The total revenue of each of the firms is

$$
T R_{A}=\left(\frac{2-f_{B}+f_{A}}{3}\right)^{2}
$$

and

$$
T R_{B}=\left(\frac{1+f_{B}-f_{A}}{3}\right)^{2} .
$$

Since $f_{A}>f_{B}, T R_{A}$ must be greater than $T R_{B}$.

To see how faddish considerations affect the equilibrium prices, consider the equilibrium when fads are irrelevant, that is were $s=0$ for all consumers. Each consumer is indifferent between the products if the difference in quality is compensated by prices,

$$
p_{A}-p_{B}=f_{A}-f_{B}
$$

Any one firm can capture the whole market by undercutting the price of the competitor. In equilibrium, $p_{B}=0$, and firm $A$ can capture the whole market by charging $p_{A}=f_{A}-f_{B}>0$, which then also is its profit.

Suppose that the better product now generates a faddish benefit. As firm $A$ can keep the whole market by choosing the price as without faddish effects, namely $f_{A}-f_{B}$, its profits cannot be reduced. It can, however, raise its price at the cost of losing those customers who value faddishness less than $\widehat{s}$ and who switch to firm $B$. Firm $A$ profits from raising its price above $f_{A}-f_{B}+p_{B}$ if

$$
\left(\frac{2+f_{A}-f_{B}}{3}\right)^{2}>f_{A}-f_{B}
$$

With $f_{A}-f_{B}<1$ this always holds.

Proposition 1 The fad effect associated with the better product enhances the quality effect, allowing the firm with the better product to charge a higher price. Consumers who little value faddishness buy the cheaper product.

Do consumers who place little value on faddishness gain or lose from the existence of some consumers who highly value buying the faddish good? If both firms are active, the price of the inferior good (bought by consumers who little value fads) is $p_{B}=\frac{1+f_{B}-f_{A}}{3}$; a buyer of this good enjoys a consumer surplus of $f_{B}-p_{B}=\frac{2 f_{B}+f_{A}-1}{3}$. If firm $A$ set a price 
so that all consumers buy its good, it sells the good at price $f_{A}-f_{B}$; a buyer's consumer surplus is $f_{A}-p_{A}=f_{B}$. So the consumer surplus of a person who little values faddishness is larger when both goods are sold if $\frac{2 f_{B}+f_{A}-1}{3}>f_{B}$, or if $f_{A}-f_{B}>1$, which can never hold.

Lemma 1 The presence of consumers who highly value faddishness can hurt consumers who do not.

Recalling the results from above, we also conclude

Proposition 2 The firm that developed a better product always has a larger market share than the other firm.

\section{A snowball}

To allow for a snowball, that is for initial success to lead to later success, we consider investment in multiple periods. We do so first with a two-period model. We provide two mechanisms which can independently explain a snowball effect, though they can be mutually reinforcing.

In period 1, as in the previous section, firms develop a new product. In period 2 both firms engage in development effort, further improving the quality of their products. A conservative assumption for our purposes is that at the end of period 1, firm $B$ can imitate firm $A$ 's product; the differences between the products produced by the two firms will thus reflect investments made in period 2 .

\subsection{Status effects among workers}

At the end of period 1, each firm has a product with quality $f_{A}^{o}$. Consider competition in period 2. Each firm chooses to invest in developing additional features, with firm $i$ spending $e_{i}$. Then the product quality in period 2 at firm $i$ is

$$
f_{i}=f_{A}^{o}+e_{i}
$$

We now extend the model to allow workers to value status: a person is willing to work at a lower wage at the firm with the better product in period 1 . This difference can arise 
if a worker's utility from employment derives both from his monetary wage and from the status associated with employment at his firm. Working at a firm known to have highquality workers could provide utility for the worker because of self-satisfaction. Or the extra utility could appear because the success of a person's employer signals his ability.

Let the status value of working at the winning firm be $s_{A}$, so that if the wage at firm $B$ is $w_{B}$, the wage at firm $A$ is $w_{A}=w_{B}-s_{A}$. Normalize the wage at firm $B$ to 1 , so that $w_{B}=1$, and $0<w_{A}=1-s_{A}<1$. Because of the value a person places on working at the better firm, $w_{A} \equiv \theta<1$.

Increased effort or increased employment is subject to increasing costs. In particular, let the cost of developing enhancement $e$ be $\theta e^{2} / 2$. We simplify notation by normalizing quality $f_{A}=0$. In period 2 , firms play a Cournot game in their R\&D, knowing that they engage in Bertrand competition when setting prices. The profits for the two firms are then

$$
\Pi_{A}=\left(\frac{2+e_{A}-e_{B}}{3}\right)^{2}-\frac{\theta}{2}\left(e_{A}\right)^{2}
$$

and

$$
\Pi_{B}=\left(\frac{1+e_{B}-e_{A}}{3}\right)^{2}-\frac{1}{2}\left(e_{B}\right)^{2} .
$$

The first-order conditions for maximizing profits are

$$
\frac{4+2\left(e_{A}-e_{B}\right)}{9}-\theta e_{A}=0
$$

and

$$
\frac{2+2\left(e_{B}-e_{A}\right)}{9}-e_{B}=0
$$

These conditions yield

$$
e_{A}=\frac{8}{21 \theta-6}
$$

and

$$
e_{B}=\frac{6 \theta-4}{21 \theta-6}
$$

Since $\theta<1$, it follows that $e_{A}>e_{B}$ : firm $A$ invests more than firm $B$ does. We also note that for both firms to engage in development, firm $A$ 's cost advantage must be limited. Necessary conditions are that $\theta>\frac{2}{7}=0.29$ and that $\theta>\frac{84}{126}=0.67$. As the last inequality is a stronger requirement, it is binding for firm $B$ to engage in R\&D.

Profits are

$$
\Pi_{A}=\frac{(144 \theta-32) \theta}{(21 \theta-6)^{2}}
$$


and

$$
\Pi_{B}=\frac{63 \theta^{2}-84 \theta+28}{(21 \theta-6)^{2}} .
$$

As $\frac{2}{3}<\theta<1, \Pi_{A}>\Pi_{B}$. Therefore, the leading firm has higher profits. The effect of $\theta$ on the profit difference is

$$
\frac{\partial}{\partial \theta}\left(\Pi_{A}-\Pi_{B}\right)=\frac{288-688 \theta}{756 \theta-2646 \theta^{2}+3087 \theta^{3}-72} .
$$

The denominator is always positive as $\frac{2}{3}<\theta<1$ and $756 \theta-2646 \theta^{2}+3087 \theta^{3}-72=$ $(7 \theta-2)(21 \theta-6)^{2}$. The numerator is always negative as it is decreasing in $\theta$ and negative at $\theta=\frac{2}{3}$. Therefore,

Proposition 3 (Snowball effect with status concerns). If workers at the better firm enjoy higher status, it can pay a lower wage. This cost advantage enables it to invest more than the other firm in developing new models of the product, and therefore to maintain its lead. The profit difference increases with the status effect.

Status concerns by workers generate a snowball effect: the initial market leader enjoys lower R\&D costs, as its employees are willing to work for a lower wage, thus enabling it to stay as market leader also in the following period.

\subsection{Corporate culture}

A firm that happened to hire good workers may also develop a better corporate culture, allowing it to produce better products in the future. In other words, for any given labor input $e$ allocated to $\mathrm{R} \& \mathrm{D}$, firm $A$ 's development efforts are more effective the better its early hires, and so the better its corporate culture. The product qualities are then

$$
\begin{aligned}
& f_{A}=f_{A}^{o}+\gamma e_{A}, \quad \gamma>1 \\
& f_{B}=f_{A}^{o}+e_{B} .
\end{aligned}
$$

It is now convenient to interpret $\gamma$ as measuring corporate culture, and ignore here status effects. As consumers are willing to pay a premium for the better product, $\Pi_{A}>\Pi_{B}$. With $\gamma>1$, the profits are

$$
\Pi_{A}=\left(\frac{2+\gamma e_{A}-e_{B}}{3}\right)^{2}-\frac{1}{2}\left(e_{A}\right)^{2}
$$


and

$$
\Pi_{B}=\left(\frac{1+e_{B}-\gamma e_{A}}{3}\right)^{2}-\frac{1}{2}\left(e_{B}\right)^{2} .
$$

The first-order conditions for maximizing profits are

$$
\frac{2\left(2-e_{B}\right) \gamma+2 \gamma^{2} e_{A}}{9}-e_{A}=0
$$

and

$$
\frac{2\left(1-\gamma e_{A}\right)+2 e_{B}}{9}-e_{B}=0
$$

Therefore,

$$
\begin{gathered}
e_{A}=\frac{8 \gamma}{21-6 \gamma^{2}}, \quad e_{B}=\frac{6-4 \gamma^{2}}{21-6 \gamma^{2}} \\
\Pi_{A}=\frac{144-32 \gamma^{2}}{\left(21-6 \gamma^{2}\right)^{2}}
\end{gathered}
$$

and

$$
\Pi_{B}=\frac{7\left(3-2 \gamma^{2}\right)^{2}}{9\left(7-2 \gamma^{2}\right)^{2}} .
$$

Clearly, investment incentives depend on the advantage firm $A$ enjoys from its better corporate culture. We have $\partial e_{A} / \partial \gamma>0$, and $\partial e_{B} / \partial \gamma<0$. The more efficient firm invests more in the next round. With $\gamma>1$, we have $e_{A}>e_{B}$. There is a stronger implication. For firm $B$ to remain in the market and to have an incentive to stay in the innovation race, firm $A$ must not have an overwhelmingly superior corporate culture. The condition for $e_{B}>0$ (and hence for a positive price) is that $\gamma \leq \sqrt{\frac{3}{2}}$. If the superior corporate culture at firm $A$ satisfies $\gamma>\sqrt{\frac{3}{2}}$, firm $B$ would be unable to charge a positive price and so would exit.

When both firms are active in the current race, the condition for $p_{B}$ to be positive is that $\gamma e_{A}-e_{B}=\frac{12 \gamma^{2}-6}{21-6 \gamma^{2}}<1$, which amounts to the condition above. The feasible range for corporate culture that keeps both firms in the $\mathrm{R} \& \mathrm{D}$ race is thus $1<\gamma<\sqrt{\frac{3}{2}}$. When the inequality is satisfied, $\Pi_{B}<\Pi_{A}$. We have thus established another snowball effect. From another angle, the winning firm pays a lower wage for an efficiency unit of labor. The effect of the corporate culture on the profit differential is given by

$$
\frac{\partial}{\partial \gamma}\left(\frac{144-32 \gamma^{2}}{\left(21-6 \gamma^{2}\right)^{2}}-\frac{7\left(3-2 \gamma^{2}\right)^{2}}{\left(21-6 \gamma^{2}\right)^{2}}\right)=\frac{4128 \gamma-1728 \gamma^{3}}{\left(21-6 \gamma^{2}\right)^{3}}
$$

By the restriction that $1<\gamma<\sqrt{\frac{3}{2}}$, the term on the last line is always positive, proving the claim. 
We summarize with

Proposition 4 (Snowball effect with corporate culture). If a firm's success arises from better worker quality, the improved corporate culture provides another and independent reason for further success. The better firm effectively pays a lower wage in efficiency units to its labor. The firm that initially had a better product will therefore continue to have the better product, and higher profits, in the next period. The profit difference increases with the corporate culture effect.

The effects of corporate culture therefore parallel those of status concerns among workers: each gives the leading firm an advantage by reducing its costs of R\&D.

\section{Large innovations}

The previous sections showed how status concerns of workers and a superior corporate culture of the market leader can generate snowball effects on the leader's profits and market share. In those sections a firm's investment had a deterministic outcome, and in equilibrium the firm that initially had the better product would also have the better product in later periods. We can interpret this as applying to incremental modifications of a known technology. But in developing new technologies (such as in the switch from analog to digital mobile phones, or from $G S M$ to $3 G$ ), the outcomes of investment may be highly uncertain: a firm with the better product under one technology may invest heavily, yet find that the other firm developed a better technology. In this section we allow for this possibility. Unlike in the previous section, we now assume that there is also investment in fundamental new technology in each period, preceding the race to develop the incremental technology for the following period. This implies that the firm which currently enjoys the larger market share may lose the race to develop the following period's underlying technology, and so earn lower profits in the future; this expected loss of market leadership may be capitalized in its stock price. ${ }^{5}$

\footnotetext{
${ }^{5}$ The gap between the market valuation of Nokia and its competitors has narrowed in 2004. Though Nokia is still the market leader, markets may be expecting Nokia to lose its leadership in the future.
} 


\subsection{Status effects among workers}

Consider the industry dynamics starting with a given state, when one firm, say $A$, developed the better technology. As before, R\&D is cheaper at firm $A$ than at firm $B$. Thus, it is more likely than is firm $B$ to develop a superior technology. Investment by firm $i$ is $e_{i}$. The effectiveness of $\mathrm{R} \& \mathrm{D}$ effort is measured by the parameter $\varepsilon$. The probability that firm $i$ develops a technology that is superior to the other firm's technology is $q_{i}$, with

$$
q_{A}=\frac{1}{2}+\varepsilon\left(e_{A}-e_{B}\right), q_{B}=\frac{1}{2}+\varepsilon\left(e_{B}-e_{A}\right), \quad \varepsilon>0 .
$$

We expect that in equilibrium, $e_{A}>e_{B}$, that is, $\frac{1}{2}+\varepsilon\left(e_{A}-e_{B}\right)>\frac{1}{2}$ making $\frac{1}{2}+\varepsilon\left(e_{B}-e_{A}\right)<$ $\frac{1}{2}$. A success for firm $A$ means that it earns a higher profit and continues to have the better product. If, however, firm $B$ produces a better technology and hence a better product, the market positions will change. The technology leader becomes the laggard and the laggard becomes the leader in the race for the next variety. The game continues indefinitely. In technical terms, there is a continuous industry dynamics with no stationary state.

To analyze the optimal current R\&D, suppose as before that in the current period firm $A$ has the better product. The discounted value of profits for firm $i$ is $V_{i}$; the profits in the current period, apart from investment in the development of future technology, are $\Pi_{i}$ as derived in the previous section. As explained in the previous sections, when consumers are willing to pay a premium for the better product, $\Pi_{A}>\Pi_{B}$.

Denote the discount rate by $r$. Recall that the relative success of the firms may change over time. Thus, $\Pi_{A}$ is not the profits of a named firm in each period, but rather the profits in any period of the firm which has the better product. Similarly, $V_{A}$ is the discounted value of expected future profits for the firm which in the period under consideration has the better product. This is also equal to the market value of the leading firm at the beginning of the period. Assume both firms plan to be active and produce, $V_{A}>0, V_{B}>0$, and $0<s<1$. Then the Bellman equations are

$$
\begin{aligned}
& r V_{A}=\max _{e_{A}}\left[\Pi_{A}+\left(\frac{1}{2}-\varepsilon\left(e_{A}-e_{B}\right)\right)\left(V_{B}-V_{A}\right)-\frac{\theta}{2} e_{A}^{2}\right] \\
& r V_{B}=\max _{e_{B}}\left[\Pi_{B}+\left(\frac{1}{2}-\varepsilon\left(e_{A}-e_{B}\right)\right)\left(V_{A}-V_{B}\right)-\frac{1}{2} e_{B}^{2}\right] .
\end{aligned}
$$

They capture the idea that the leading firm experiences a capital loss if it loses its position, while the lagging firm experiences a capital gain if it catches up, and passes, the 
leader. With such forward-looking behavior, solutions for optimal investments are

$$
e_{A}=\frac{\varepsilon}{\theta}\left(V_{A}-V_{B}\right)
$$

and

$$
e_{B}=\varepsilon\left(V_{A}-V_{B}\right)
$$

Then

$$
\varepsilon\left(e_{A}-e_{B}\right)=\varepsilon^{2} \frac{1-\theta}{\theta}\left(V_{A}-V_{B}\right) .
$$

With $\theta<1$, we must have $e_{A}>e_{B}$ : the status effect among workers makes the firm that was better in period 1 invest more in $R \& D$ than the other firm.

Inserting (18) and (19) into the Bellman equations gives

$$
\begin{aligned}
& r V_{A}=\Pi_{A}+\left(\frac{1}{2}-\varepsilon^{2} \frac{1-\theta}{\theta}\left(V_{A}-V_{B}\right)\right)\left(V_{B}-V_{A}\right)-\frac{\varepsilon^{2}}{2 \theta}\left(V_{A}-V_{B}\right)^{2} \\
& r V_{B}=\Pi_{B}+\left(\frac{1}{2}-\varepsilon^{2} \frac{1-\theta}{\theta}\left(V_{A}-V_{B}\right)\right)\left(V_{A}-V_{B}\right)-\frac{\varepsilon^{2}}{2}\left(V_{A}-V_{B}\right)^{2}
\end{aligned}
$$

Subtracting, we get

$$
r\left(V_{A}-V_{B}\right)=\Pi_{A}-\Pi_{B}+\left(2 \varepsilon^{2} \frac{1-\theta}{\theta}\left(V_{A}-V_{B}\right)-1\right)\left(V_{A}-V_{B}\right)-\varepsilon^{2} \frac{1-\theta}{2 \theta}\left(V_{A}-V_{B}\right)^{2} .
$$

Thus, and denoting $\Delta \equiv V_{A}-V_{B}$, we find that $\Delta$ follows the dynamics

$$
\frac{3}{2} \varepsilon^{2} \frac{1-\theta}{\theta} \Delta^{2}-(1+r) \Delta+\left(\Pi_{A}-\Pi_{B}\right)=0 .
$$

This equation has two roots. Only one can be relevant, as an increase in the difference in current profit $\Pi_{A}-\Pi_{B}$ must raise the value differential $\Delta$. We thus have the solution

$$
\Delta=\frac{1+r-\sqrt{(1+r)^{2}-6 \varepsilon^{2} \frac{1-\theta}{\theta}\left(\Pi_{A}-\Pi_{B}\right)}}{3 \varepsilon^{2} \frac{1-\theta}{\theta}} .
$$

For the sake of comparison, suppose for the moment that the more successful firm in an initial period maintains a permanent instead of a temporary advantage. Then a steady-state equilibrium exists with

$$
\widehat{\Delta}=\widehat{V_{A}}-\widehat{V_{B}}=\frac{\widehat{\Pi_{A}}-\widehat{\Pi_{B}}}{r} .
$$

With probabilistic success, however, the better firm in one period must engage in costly investment to maintain its superior technology, reducing its value and facing the risk of falling behind. We thus expect that throughout the dynamic path $\Delta_{t}<\widehat{\Delta}$ for $t \geq 1$. 
To calculate the effect of changes in the status parameter $\theta$ and in the parameter $\varepsilon$, measuring the effect of research input on the probability of success in developing a new technology, we resort to numerical analysis. The value difference can be written as

$$
\Delta=\frac{1+r}{3 \varepsilon^{2}} \frac{\theta}{1-\theta}-\sqrt{\left(\frac{1+r}{3 \varepsilon^{2}}\right)^{2} \frac{\theta^{2}}{(1-\theta)^{2}}-\frac{2}{3 \varepsilon^{2}} \frac{52 \theta^{2}+81 \theta^{3}-28 \theta}{(1-\theta)(21 \theta-6)^{2}}} .
$$

If the responsiveness parameter $\varepsilon$ and the cost advantage $1-\theta$ of the leading firm are sufficiently high, then the lagging firm may be unable to catch up with the leader. To restrict our analysis to markets where the lagging firm may overtake the leading firm, we constrain $\varepsilon$ to values sufficiently low to guarantee that the term under the square root is non-negative for all values of $r$ and $\theta$, including $r=0$ and $\theta=\frac{2}{3}$. Inserting these values into the expression under the square root in the previous formula implies that $\varepsilon^{2}$ must be less than $1 / 2$.

Our numerical analysis, in which we exclude those parameter values which violate the condition that both firms are active, shows that

Remark 1 The value difference in favor of the leading firm increases with the status effect, $\partial \Delta / \partial \theta<0$, and in the responsiveness parameter, $\partial \Delta / \partial \varepsilon>0$, for all values $\varepsilon^{2} \in$ $[0.01,0.5], r \in[0,1], \theta \in[0.67,0.99]$.

Therefore, numerical analysis confirms the intuition: if the competitive advantage of the leading firm improves, whether by making the probability of developing a better new technology more responsive to R\&D investment, or by increasing its cost advantage $1-\theta$, the market value of the leading firm increases relative to the lagging firm. The comparative statics results hold also in all tests performed outside the reported parameter values.

\subsection{Corporate culture}

We showed above how status concerns of workers can generate a snowball effect when firms develop a new technology. We consider next the effect of superior corporate culture, showing that it can also generate snowball effects.

Introduce then the probabilities of developing a superior technology as

$$
q_{A}=\frac{1}{2}+\varepsilon\left(\gamma e_{A}-e_{B}\right), q_{B}=\frac{1}{2}+\varepsilon\left(e_{B}-\gamma e_{A}\right), \quad \varepsilon>0
$$


with $\gamma>1$. The Bellman equations are

$$
\begin{aligned}
& r V_{A}=\max _{e_{A}}\left[\Pi_{A}+\left(\frac{1}{2}-\varepsilon\left(\gamma e_{A}-e_{B}\right)\right)\left(V_{B}-V_{A}\right)-\frac{1}{2} e_{A}^{2}\right] \\
& r V_{B}=\max _{e_{B}}\left[\Pi_{B}+\left(\frac{1}{2}-\varepsilon\left(\gamma e_{A}-e_{B}\right)\right)\left(V_{A}-V_{B}\right)-\frac{1}{2} e_{B}^{2}\right] .
\end{aligned}
$$

The optimal R\&D efforts satisfy

$$
e_{A}=\gamma \varepsilon\left(V_{A}-V_{B}\right)
$$

and

$$
e_{B}=\varepsilon\left(V_{A}-V_{B}\right)
$$

Denoting the value difference then by $\Delta^{\prime}$ and solving for the profit difference $\Pi_{A}-\Pi_{B}=$ $\frac{52 \gamma^{2}-28 \gamma^{4}+81}{\left(21-6 \gamma^{2}\right)^{2}}$, we find

$$
\Delta^{\prime}=\frac{1+r-\sqrt{(1+r)^{2}-6 \varepsilon^{2}\left(\gamma^{2}-1\right)\left(\frac{52 \gamma^{2}-28 \gamma^{4}+81}{\left(21-6 \gamma^{2}\right)^{2}}\right)}}{3 \varepsilon^{2}\left(\gamma^{2}-1\right)} .
$$

If the responsiveness parameter $\varepsilon$ and the effectiveness advantage $\gamma$ of the leading firm are sufficiently high, then the lagging firm may be unable to catch up with the leader. To restrict our analysis to markets where the lagging firm may overtake the leading firm, we constrain $\varepsilon$ to values which are sufficiently low to guarantee that the term under the square root is non-negative for all values of $r$ and $\gamma$, including $r=0$ and $\gamma^{2}=\frac{3}{2}$. This restriction implies that

$$
\varepsilon^{2}<\frac{1}{2}
$$

Our numerical analysis, in which we exclude those parameter values violating the condition that both firms are active, shows that

Remark 2 The value difference in favor of the leading firm increases with the corporate culture advantage parameter, $\partial \Delta^{\prime} / \partial \gamma>0$, and in the responsiveness parameter, $\partial \Delta / \partial \varepsilon>$ 0, for all values $\varepsilon^{2} \in[0.01,0.49], r \in[0,1], \gamma^{2} \in[1.01,1.5]$.

As with the status effect, numerical analysis confirms the intuition with corporate culture: if the competitive advantage of the leading firm improves, whether by making the probability of developing a better new technology more responsive to $R \& D$ investment, or by increasing its effectiveness $\gamma$, the market value of the leading firm increases relative 
to the lagging firm. The comparative statics results also held in all calculations performed outside the reported parameter values.

We collect the results above with

Proposition 5 When the industry dynamics are characterized by probabilistic success, the firm with a better product in any period finds it optimal to invest more in RED than does the other firm. The status effect among its workers reduces the investment cost and gives an incentive to take advantage of the resulting snowball effect. A more efficient corporate culture has similar effects.

There are several ways in which our model could be extended. The finding in the previous section (that with overwhelmingly superior technology $\gamma>\sqrt{\frac{3}{2}}$, the losing firm abstains from current development effort and market activity) means that in the dynamic model of the current section, $\Pi_{B}=0$. The current model, however, suggests that firm $B$ may nevertheless compete in developing a new technology. Lastly, we note a possibility for multiple equilibria. Suppose that one firm expects the other to develop the better product. This solidifies the winner's position, and is self-enforcing. A laggard, however, who expects to win the next round with sufficiently high probability, will invest heavily, which makes success more likely.

\section{Concluding remarks}

The model above explained corporate success in terms of initial luck in hiring talented workers and the subsequent snowball effect, making evolution of an industry path-dependent. Such a proposal has some novelty when contrasted to earlier papers on industry dynamics.

Our model may also explain some other behavior. Consider unemployment. The puzzle of unemployment is why people who are willing to work at the market wage are not hired. One answer would rest on the reputational externality discussed above. A low-quality worker could increase output, and generate more revenue for firm than his wage. But if he is hired, the reputation of workers in the firm will decline, and other workers will demand a higher wage. The firm may therefore not want to hire additional low-quality workers.

The idea of established corporate culture has another implication worth exploring. Suppose that workers, after developing valuable skills, exploit their bargaining power by 
seeking competing job offers from the rival firm. The lagging firm, in particular, might seek to attract high-quality workers from the competitor. But since working at the laggard firm confers no favorable status, it must pay a higher wage. Corporate culture, especially when embedded in workers, reduces the inter-firm mobility of workers.

Our model also yields testable implications: 1) The wage distribution differs from the distribution of productivity. 2) In human-capital intensive industries, leading firms pay lower wages for workers of similar talent than do lagging firms. 3) In a market with heterogeneous products, price differences often exceed differences in quality. 4) A firm with a small initial lead may often expand its lead in later periods. 5) Though technological leadership in an industry tends to be maintained with the introduction of new technologies, positions of leadership are lost over time with positive probability.

\section{Acknowledgement}

An earlier draft of this paper was presented at the CESifo Area Conference on Industrial Organization, Munich, March 12-13, 2004. The authors are indebted to Kai Konrad, Vivek Ghosal and other participants for helpful comments. We are also grateful to Thomas Rønde for his suggestions.

\section{References}

[1] Arnott, R. and J. Rowse (1987) "Peer group effects and educational attainment." Journal of Public Economics, 32: 287-305.

[2] Arrow, Kenneth J. (1962) "The economic implications of learning by doing." Review of Economic Studies, 29(3): 155-173.

[3] Arrow, Kenneth (1972) "Some mathematical models of race discrimination in the labor market." In A.H. Pascal, ed. Racial Discrimination in Economic Life Lexington MA., pp. 187-203.

[4] Arrow, Kenneth J. (1974) The Limits of Organization. New York: W. W. Norton \& Co. 
[5] Athey, Susan and Armin Schmutzler (2001) "Investment and market dominance." Rand Journal of Economics, 32(1): 1-26.

[6] Becker, Gary S. (1957) The Economics of Discrimination. Chicago: University of Chicago Press.

[7] Berglas, E. (1976) "Distribution of tastes and skills and the provision of local public goods." Journal of Public Economics, 6: 409-423.

[8] Borjas, George J. (1982) "The politics of employment administration in the federal bureaucracy." Journal of Law and Economics, 25(2): 271-300.

[9] Brueckner, Jan K. (1989) "Club theory with a peer-group effect." Regional Science and Urban Economics, 19: 399-420.

[10] Brueckner, Jan K. and K. Lee (1991) "Tastes, skills, and local public goods." Paper presented at the conference on New Directions in Club Theory, Tampere.

[11] Cabral, Luís M. B. (2002) "Increasing dominance with no efficiency effect." Journal of Economic Theory, 102(2): 471-479.

[12] de Bartolome, C.A.M. (1990) "Equilibrium and inefficiency in a community model with peer group effects." Journal of Political Economy, 98: 110-133.

[13] Epple, Dennis and Richard E. Romano (1998) "Competition between private and public schools, vouchers, and peer-group effects." American Economic Review, 88(1): 33-62.

[14] Ericson, Richard and Ariel Pakes (1995) "Markov-perfect industry dynamics: A framework for empirical work." Review of Economic Studies, 62(1): 53-82.

[15] Fershtman, C., Y. Weiss, , and H.K. Hvide (2001) "Status concerns and the organization of work", WP No. 2-2001, Tel-Aviv University.

[16] Frank, Robert H. (1984a) "Interdependent preferences and the competitive wage structure." RAND Journal of Economics, 15: 510-520.

[17] Frank, Robert H. (1984b) "Are workers paid their marginal products?. American Economic Review, 74: 549-571. 
[18] Frank, Robert H. (1985a) "The demand for unobservable and other nonpositional goods." American Economic Review, 75: 101-116.

[19] Frank, Robert H. (1985b), Choosing the Right Pond, Human Behavior and the Quest for Status (New York, Oxford University Press).

[20] Ghemawat, P. (1990) "The snowball effect." International Journal of Industrial Organization, 8: 335-351.

[21] Hermalin, Benjamin E. (1994) "Heterogeneity in organizational form: Why otherwise identical firms choose different incentives for their managers." RAND Journal of Economics, 25(4): 518-537.

[22] Hermalin, Benjamin E. (2000) "Economics \& corporate culture." University of California, Berkeley.

[23] Hopenhayn, Hugo (1992) "Entry, exit, and firm dynamics in long run equilibrium." Econometrica, 60(5): 1127-1150.

[24] Jovanovic, Boyan (1979) "Job matching and the theory of turnover." Journal of Political Economy, 87(5): 972-990.

[25] Jovanovic, Boyan (1982) "Selection and the evolution of industry, Econometrica, $50(3): 649-670$.

[26] Jovanovic, Boyan and Glenn M. MacDonald (1994) "The life cycle of a competitive industry." Journal of Political Economy, 102(2): 322-347.

[27] Klepper, Steven (1996) "Entry, exit, growth and innovation over the product life cycle." American Economic Review 86(3): 562-583.

[28] Lazear, Edward P. (1995) "Corporate culture and the diffusion of values." In Horst Siebert, ed., Trends in Business Organization, Tubingen, Germany: J. C. B. Mohr ( Paul Siebeck)

[29] Ma, Jinpeng (2001) "Job matching and coalition formation with utility or disutility of co-workers." Games and Economic Behavior, 34(1): 83-103. 
[30] McGuire M. C. (1991) "Group composition, collective consumption, and collaborative production." American Economic Review, 81(5): 1391-1407.

[31] Mill, John S. (1847), Principles of Political Economy (London, Longmans, Green and Co., 1911).

[32] Prescott, E. and Visscher Michael (1980) "Organization capital." Journal of Political Economy, 88(3): 446-461.

[33] Rae, John (1834) The Sociological Theory of Capital. (New York, Macmillan).

[34] Rosen, Sherwin (1972) "Learning by experience as joint production." Quarterly Journal of Economics, 86 (3): 366-382.

[35] Scotchmer, S. (1992) "Public goods and the invisible hand," Working Paper Number 177, U.C., Berkeley. 